\title{
Hispanic Heritage Month
}

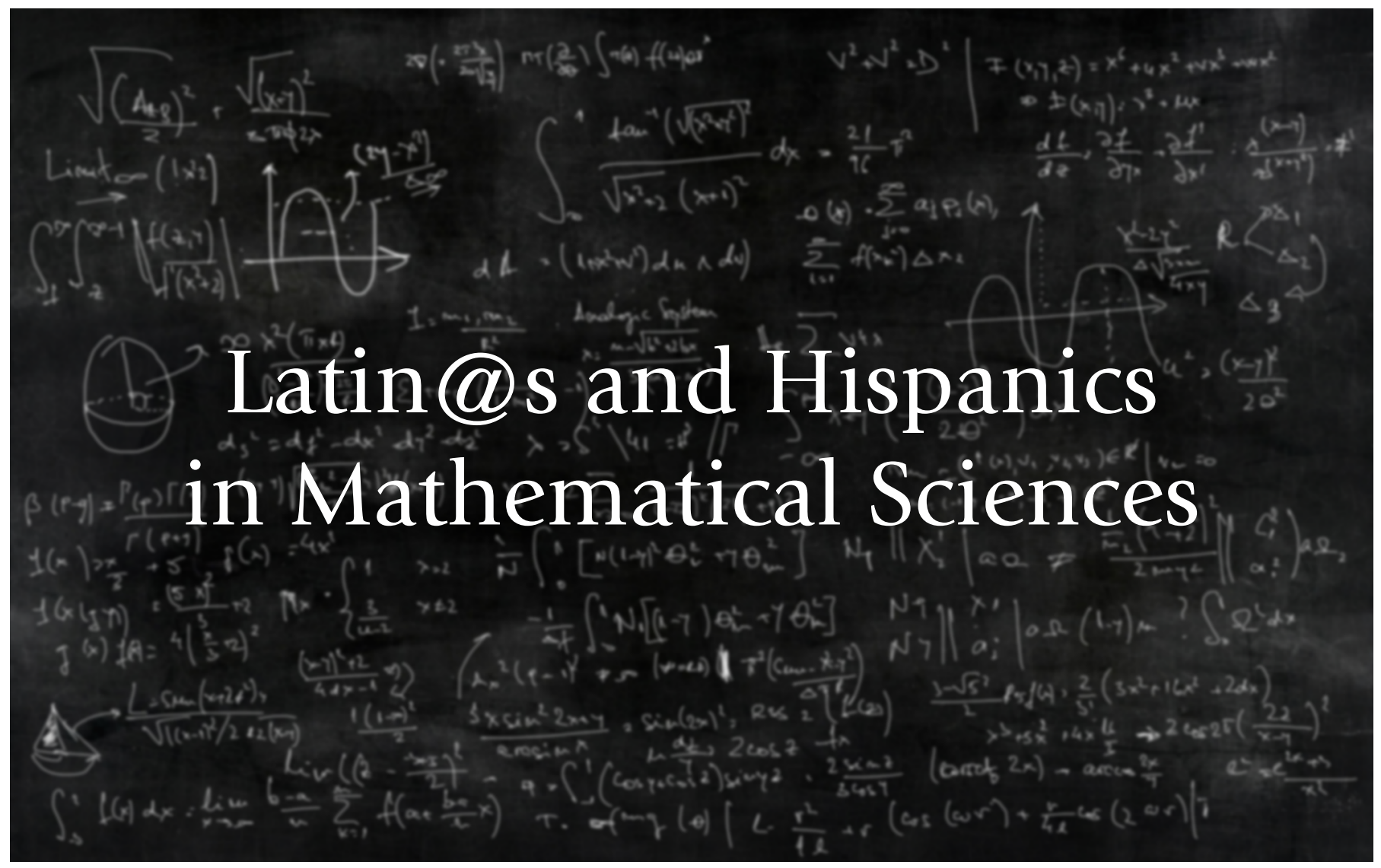

\section{Ricardo Cortez}

Hispanic Heritage Month ${ }^{1}$ is a national observance that recognizes the contributions made by an estimated 57 million Latinos and Hispanics in the US and celebrates their heritage and culture. Notices has taken this opportunity to highlight selected new mathematical contributions by Latinos and Hispanics. The topics of the articles in this issue include an introduction to algebraic statistics, the geometry of matroids, the use of partial differential equations in movie animation, and collaborative mathematics education. Another article showcases six up-and-coming mathematicians to be featured in 1athi sms . org. While the focus is on mathematics, the issue also includes an article about an undocumented student's path to a successful

Ricardo Cortez is the Pendergraft William Larkin Duren Professor of mathematics at Tulane University. His email address is rcortez atulane.edu.

${ }^{1}$ September 15-October 15, https://www.hispanicheritage month.org

For permission to reprint this article, please contact: reprint-permission@ams.org.

DOI: http://dx.doi.org/10.1090/noti1720 mathematical career and an article about the challenges faced by Puerto Rican mathematicians in the aftermath of Hurricane Maria.

Readers will notice that there is no delineated section for Latinos in this issue. Instead the articles are interspersed throughout the issue, reflecting my view that work done by groups underrepresented in mathematics should be part of the mainstream. When we talk about underrepresentation in the mathematical sciences, we acknowledge that there is a troubling discrepancy between the 18 percent of the US population that is Latino and the 4 percent of the doctoral degrees in mathematics and statistics earned by Latinos. ${ }^{2}$ The Hispanic Heritage Month issue of the Notices is a reminder that Latin@s make significant contributions in mathematics and that it takes the entire mathematics community to increase representation.

${ }^{2}$ Women, Minorities, and Persons with Disabilities in Science and Engineering: 2017. Special Report NSF 17-310, table 7-7. www.nsf.gov/statistics/wmpd. 